\title{
Dilemmas in Rescue and Reintegration: A critical assessment of India's policies for children trafficked for labour exploitation
}

Elizabeth Donger and Jacqueline Bhabha

\begin{abstract}
This paper provides a comprehensive analysis of the Indian government's efforts to combat pervasive child trafficking for labour exploitation through rescue and reintegration of affected children. It evaluates the extensive policy and legal frameworks against on-the-ground realities in the states of Bihar and Rajasthan, using empirical findings from a qualitative study carried out by the FXB Center for Health \& Human Rights at Harvard University. The results demonstrate that current practices fail to adhere to human rights norms or protect rescued children from risk of future exploitation. They underscore important challenges in the rescue and reintegration of trafficked children, and call into question the singular focus on this category of post-harm response over preventative interventions. The findings point to a critical need for future research, sustained multi-stakeholder discussion and concrete reforms.
\end{abstract}

Keywords: prevention, rescue, reintegration, trafficking, child labour, India, exploitation

Please cite this article as: E Donger and J Bhabha, 'Dilemmas in Rescue and Reintegration: A critical assessment of India's policies for children trafficked for labour exploitation', Anti-Trafficking Review, issue 10, 2018, pp. 52-69, www.antitraffickingreview.org

\section{Introduction}

The trafficking of children for labour exploitation is a gross violation of rights that both results from and contributes to structural poverty and inequality. From a protection standpoint, the prevailing model of response to this problem is 'rescue and reintegration': remove children from harm, then support their recovery and social and economic inclusion. In India, pervasive trafficking for labour exploitation has attracted considerable public concern and academic analysis. However, state interventions to rescue and reintegrate children trafficked for labour exploitation have not been carefully evaluated. This gap is significant because the quality and course of a child's life after trafficking, while determined partly by complex individual, family and community factors, also depends upon the effectiveness of the systems mandated to provide the child with services and support.

This paper evaluates the existing legal and policy frameworks for rescue and reintegration against the realities of their implementation in one substantial child labour trafficking context: rural children trafficked from the impoverished eastern state of Bihar a thousand kilometres to the west-Jaipur-the thriving capital of India's largest state, Rajasthan. The analysis is based on empirical findings from a qualitative study conducted by the FXB Center for Health \& Human Rights at Harvard University (Harvard FXB) with relevant duty bearers in the rescue and reintegration process. The results reveal startling inconsistencies between legal and policy commitments and implementation. The underlying structural factors causing children's abuse are not sufficiently addressed. Victims, if they do not fall through the cracks entirely, receive a series of poorly executed, disjointed and fragmented services.

This paper argues that the substantial challenges associated with addressing trafficked children's complex vulnerabilities post-harm underscore a need for interventions targeting these vulnerabilities before harm occurs: prioritising prevention. In the absence of comprehensive and holistic solutions, however, at least those adopted should minimise harm and maximise protective outcomes. The analysis advanced in this paper highlights several key challenges to the current prevailing model and suggests concrete priorities for reforms to ensure efforts are more effective, better coordinated and longer lasting. 


\section{Context}

International law defines child trafficking as the act of recruitment, transportation, transfer, harbouring or receipt of a child, either within or outside a country, for the purpose of exploitation. ${ }^{1}$ Labour exploitation is one pervasive manifestation of trafficking. Child labour is defined by international law as work that is unacceptable for children, because the child is too young to enter employment, or the work concerned is hazardous or another so-called 'Worst Form of Child Labour'. ${ }^{2}$ Whether all child labour amounts to exploitation, the necessary second element of child trafficking as just defined, is a matter of some debate and influenced by divergent national legal and cultural contexts. ${ }^{3}$

In India, the recruitment of children for unquestionably exploitative work is a widely acknowledged problem. ${ }^{4}$ Children are trafficked because of complex push-and-pull factors including structural poverty, climate change and human rights violations on the one hand and the promise of improved opportunities and a better life on the other. Recruitment happens through strangers, middlemen familiar to communities, or relatives. The process can involve forcible kidnap, but more frequently involves pressure and/or deception, including false promises around conditions of work and pay. Typically, parents are the targets, for they hand over the children to the recruiters, sometimes in return for a small lump sum intended as part credit against the child's future wages. On occasion, however, children themselves voluntarily leave in search of work and end up in situations of exploitation at destination.

Children's employment circumstances are varied and include carpet making, ${ }^{5}$ garment factories, ${ }^{6}$ brick kilns, tea stalls, and the domestic sphere. Many of these children work long hours in conditions that pose severe health hazards. Often restricted to the confines of the workplace, they may be isolated from basic protective structures like family, education or welfare provision. As a result, they are highly vulnerable to physical, emotional and sexual abuse.

Statistics on the magnitude of this problem are scarce, variable and unreliable. Some experts now consider largely meaningless the sizeable figures customarily cited as proxies for the seriousness of the problem. ${ }^{7}$ Quantitative data are largely collected from sporadic studies and surveys, and extrapolated based on approximations. The International Labour Organization estimates that over 5.7 million 5-17-year-olds in India are engaged in child labour, ${ }^{8}$ an unknown portion of whom are trafficked. By contrast, figures released for 2015 by the National Crime Records Bureau report only 3,490 cases of child trafficking covering all forms of exploitation. ${ }^{9}$

Over decades, the Government of India has developed an extensive legal and policy framework to address the intertwined issues of child labour and child trafficking. Most notably, this includes The Child Labour (Probibition

1 UN General Assembly, Protocol to Prevent, Suppress and Punish Trafficking in Persons, Especially Women and Children, 15 November 2000, (Trafficking Protocol), Article 3.

2 International Labour Organization (ILO), Minimum Age Convention, C138, 26 June 1973; ILO, Worst Forms of Child Labour Convention, C182, 17 June 1999.

3 M Liebel, 'Do Children Have a Right to Work? Working children's movements in the struggle for social justice' in K Hanson and O Nieuwenhuys (eds.), Reconceptualizing Children's Rights in International Development, Cambridge University Press, Cambridge, 2013, pp. 225-249.

4 P M Nair, Trafficking in Women and Children in India, Orient Longman, New Delhi, 2005, pp. 131-139.

5 T Chubayanger, Migrant and Trafficked Children in Hazardous Employment: The case of Nagaland, Noida, 2013, http://www.vvgnli.gov.in/sites/default/ files/2013-103.pdf.

6 Global March Against Child Labour, Dirty Cotton: A research on child labour, slavery, trafficking and exploitation in cotton and cotton seed farming in India, New Delhi, 2012.

7 S Yea and B Gerasimov (eds.), 'Where's the Evidence?', Anti-Trafficking Review, issue 8, April 2017; National Commission for the Protection of Child Rights, 'Right to Education and Total Abolition of Child Labour: Freedom and dignity for all children', Briefing Papers, 2008, p. 1, http://ncpcr.gov.in/showfile.php?lid=138.

8 S Khan and S Lyon, Measuring Children's Work in South Asia: Perspectives from national household surveys, International Labour Organization, 2015, p. 81.

9 National Crime Records Bureau, Crime in India: 2015, Ministry of Home Affairs, p. 217, http://ncrb.nic.in/StatPublications/CII/CII2015/FILES/Statistics-2015_rev1_1.pdf. 
and Regulation) Act, 1986, and its 2016 Amendment. The 2016 amendment, while continuing the previous prohibition on work by children below 14 years of age and work in certain hazardous occupations for all children under 18, introduces some far-reaching exceptions. Children below 14 are now allowed to work in the domestic sphere or family businesses, contexts affording considerable leeway for exploitation. Other relevant elements of the Indian legal framework are The Jwvenile Justice (Care and Protection of Cbildren) Act, 2000, and The Right of Children to Free and Compulsory Education Act, 2009 (providing all children aged 6 to 14 years with free and compulsory education).

The country's flagship National Child Labour Project (NCLP) was created in 1988 to 'suitably rehabilitate children withdrawn from employment'. ${ }^{10}$ Other programmes were subsequently created to provide complementary services to children not covered by the NCLP. In September 2006, the Ministry of Home Affairs established the Anti Human Trafficking Units (AHTUs) to facilitate interagency coordination for rescue and reintegration efforts, monitor interventions, and collect and analyse relevant data. ${ }^{11}$

In 2008, the Ministry of Labour and Employment published the first consolidated rescue and reintegration guidelines for children trafficked for labour. The Protocol on Prevention, Rescue, Repatriation and Rehabilitation of Trafficked \& Migrant Child Labour (The Protocol) was intended to provide 'clearly laid out mechanisms and supporting instructions, which could be relied upon by various stakeholders for taking all the necessary steps'.12 This document, which does not reference the AHTUs, has since been supplemented by local and state government action plans. ${ }^{13}$

\section{Field Research Methodology}

The analysis presented here is based on field research conducted by the Harvard FXB Center between 2014 and 2015. ${ }^{14} \mathrm{FXB}$ India Suraksha, a registered Indian NGO, conducted the research in the source state of Bihar, the transit city of New Delhi, and the destination state of Rajasthan. ${ }^{15}$

The study involved extensive, semi-structured interviews with 49 key informants from the Department of Labour (8), other federal and state government representatives (8), the Child Welfare Committees (CWCs) in both destination and home states of trafficked children (5), law enforcement (10), and non-profit organisations (18). The study was originally planned to include interviews with trafficked children to better understand their perspectives on the recruitment, rescue and reintegration process, but the Harvard Institutional Review Board ruled this out due to ethical concerns about the risk of re-traumatisation or retaliatory action by parents. As a result, no direct information was collected from the trafficked children themselves. A standardised questionnaire was developed and partially adapted for each subgroup, reflecting specific responsibilities for and expertise on the rescue and reintegration process. Informants were interviewed in Hindi and/or English in private, secure locations outside the workplace. The identities and employment positions of respondents were anonymised.

10 Ministry of Labour \& Employment, Government of India, National Policy on Child Labour - 1987.

11 As of August 2012, there were AHTUs in 225 of India's 640 districts. See: Ministry of Home Affairs, Government of India, Human Trafficking in Assam, 12 August 2015, http://mha1.nic.in/par2013/par2015-pdfs/rs-120815/2594.pdf; United Nations Office on Drugs and Crime (UNODC), Current Status of Victim Service Providers and Criminal Justice Actors in India, 2013, pp. 29-30.

12 Ministry of Labour and Employment, Government of India, Protocol on Prevention, Rescue, Repatriation and Rebabilitation of Trafficked and Migrant Child Labour, 2008, p. 8, http://pblabour.gov.in/Pdfs/protocol.pdf.

13 UNODC, p. 84.

14 The Principal Investigator of this study was Jacqueline Bhabha, Director of Research at the Harvard FXB Center. The research team consisted of Angela Duger, a Research Associate at the Harvard FXB Center, and Satya Prakash, Senior Programme Manager at FXB India Suraksha based in New Delhi.

15 According to the UNODC, 'The State of Bihar is a source area for trafficking of children for forced labour. Thousands of children are trafficked every year to work in towns or cities in various unorganised sectors of work.' Child trafficking is also 'a serious issue' in Rajasthan, which is 'a source of child labour...but also a destination state for child labour as a large number of children from West Bengal, Bihar, Uttar Pradesh, Delhi and Jharkhand come to Rajasthan for work'. See: UNODC, pp. 72, 141. 


\section{Rescue Operations}

The Protocol provides general guidelines for planning and execution of raids in 'an effective, child friendly manner [that is] less traumatic for the child', ${ }^{16}$ as well as immediate post-rescue steps. The Harvard FXB survey shows that rescue operations in Bihar and Rajasthan are largely successful in physically removing a limited number of children from exploitative work environments following raids on their workplaces. However, operations are carried out inconsistently by poorly trained staff, unsupported by centralised intelligence systems, and often expose children to additional trauma and risk. There are significant gaps in the content and implementation of policies for planning and executing raids.

According to the Protocol, rescue teams should include: an official from the Department of Labour, representatives of the CWCs, a local non-profit, a doctor, and a female police officer or volunteer. ${ }^{17}$ These individuals must receive training on relevant laws, their individual responsibilities, and trauma prevention strategies. However, research participants reported that, in reality, teams are often too small to cope with the numbers of children needing rescue. Police officers, doctors, and female witnesses only sporadically take part. The AHTUs, whose core mandate is to coordinate rescue and post-rescue procedures, scarcely participate in the process.

In the absence of a clear allocation of responsibility between the different entities listed in the Protocol, rescue operations in practice rely heavily on non-profit organisations. While several organisations, such as Bachpan Bachao Andolan, have considerable expertise in conducting raids, key informant data suggests this overreliance leads to ad hoc and under-resourced raids directed by inexperienced or poorly supported workers, a situation that can and does inflict additional trauma on vulnerable children. One respondent noted that NGOs sometimes proceed with a rescue on their own: 'Most of the time, when we don't take immediate action the child could be sent somewhere else. So we don't inform anyone. My first priority is to rescue the child, and then inform others.' Non-profit participants reported suffering threats, stone attacks, and beatings in retaliation for their actions. These risks of reprisal are exacerbated by the non-involvement of law enforcement in raids.

The Protocol states that details of the rescue and the identities of rescued children must remain strictly confidential, and should not be disclosed to outside parties, including the media. ${ }^{18}$ Yet privacy breaches concerning occurrences and information leaks before, during and after raids are frequent. Respondents stated that employers are often alerted to impending raids, and that unsuccessful rescue operations can increase the risk of employers retaliating against children. Basic precautions to protect children's identities are often neglected. One government official stated that rescue team members directly solicit media involvement so 'the public could understand that this type of activity is a crime and punishable offence'. Publicity generates risks of retaliation against rescued children, increased social stigma and difficulty in reintegration. Moreover, widespread sensationalised media coverage of raids plays an important role in simplifying the complex underlying social and economic problems that perpetuate this problem. ${ }^{19}$

Following rescue, children should be taken to 'drop-in centers or temporary shelter homes under the control of Social Welfare Department' until arrangements for more permanent accommodation are made. They should be accompanied to the CWC as soon as possible after their rescue to make a statement about their experience. The CWC serves as 'guardian of the rescued child...empowered to plan the rehabilitation plan'. ${ }^{20}$ Immediate care and support are also of critical importance as a prelude to more sustained rehabilitation and reintegration into a rights-respecting childhood. In practice, while basic food and shelter are generally provided immediately following rescue, care is often insufficient. Several NGO participants reported that rescued children are

\footnotetext{
Protocol on Prevention, Rescue, Repatriation and Rehabilitation, p. 25.

Ibid., p. 24.

Ibid., pp. 23, 26.

19 See, for example, K A Appiah and M Bunzl (eds.), Buying Freedom: The ethics and economics of slave redemption, Princeton University, Princeton, 2007, p. 9; M Ditmore, The Use of Raids to Fight Trafficking in Persons, Sex Workers Project, 2009 , http://sexworkersproject.org/downloads/swp-2009-raids-and-trafficking-report.pdf; Global Alliance Against Traffic in Women, Collateral Damage: The impact of anti-trafficking measures on buman rights around the world, Bangkok, 2007.

20 Protocol on Prevention, Rescue, Repatriation and Rehabilitation, p. 30.
} 
sometimes transferred to a police station, an inappropriate and potentially re-traumatising environment. According to 45 of 49 participants, the care of children trafficked from different states is inhibited by the simple lack of an interpreter competent in the relevant local languages. This striking failure has wide implications for the effectiveness of service delivery and likelihood of ensuing criminal prosecution.

Criminal proceedings are also meant to be initiated at the immediate post-rescue stage, an important element in curtailing demand for exploitative child labour. Labour department officials are required to file a First Information Report (FIR), starting an investigation and potential prosecution of a crime. ${ }^{21}$ In practice, respondents stated that FIRs are not always filed and that there is confusion and disagreement about who has this responsibility. The resulting consensus is that employers are 'rarely' or 'never' arrested, and unlikely to be convicted. Official figures for 2015 show that nationwide only 55 cases of child trafficking for any purpose (1.09 per cent) resulted in convictions out of 5,026 under investigation. ${ }^{22}$

\section{Reintegration}

Following their rescue, the children face extensive challenges in successfully reintegrating into society. While the concept has no universally accepted definition, 'reintegration' is broadly understood in the literature to encompass a long-term, holistic process. Surtees defines it as:

A process of recovery and economic and social inclusion... [which] includes settlement in a stable and safe environment, access to a reasonable standard of living, mental and physical wellbeing, and opportunities for personal, social and economic development, and access to social and emotional support. $^{23}$

Existing reintegration strategy in India focuses primarily on the provision of 'educational rehabilitation for the child and economic rehabilitation for the family'. ${ }^{24}$ The Harvard FXB study demonstrates, however, that current reintegration strategies in Bihar and Rajasthan fail to respect trafficked children and their families' fundamental needs and rights, including protection, adequate standards of living, health care, and education.

Indian anti-trafficking practitioners treat reintegration as a fixed, short-term process. Ninety-six per cent of respondents interviewed stated that individual children's cases are closed within only four months of rescue, with no subsequent follow-up or monitoring of the consequences of return. Both short- and long-term reintegration plans for rescued children and their families are rarely prepared or implemented. Rather, existing reintegration efforts amount to the simple tracing of and immediate return of rescued children to their families, leaving them exposed to the same structural vulnerabilities that led to their being originally trafficked.

Regarding accommodation, the CWC has an obligation to allocate appropriate housing to rescued children. The Protocol requires a home verification report to determine whether it is safe for the child to be sent back home to his or her family. If not, the CWC can recommend family-based alternative care, or residential hostels provided by the government or non-profits. ${ }^{25}$ In practice, children are always returned to their families except in cases where the family cannot be located. Respondents agreed that thorough family assessments, exploring the original drivers of the child's trafficking and measures that could alleviate risks of re-trafficking, never happen.

This serious protection failure is due in part to the logistical difficulties of home assessment. Approximately, four-fifths of child workers in India are from low-caste families in remote and hard-to-reach rural areas, ${ }^{26}$ and trafficked children sometimes come from families that are themselves migratory, struggling to survive. The challenges facing CWCs seeking to conduct home visits are therefore substantial and require staffing, training

\footnotetext{
Ibid., p. 21.

National Crime Records Bureau, pp. 217-221.

R Surtees, Monitoring Anti-Trafficking Re/integration Programs: A manual, Nexus Institute, Washington DC, 2010, p. 24.

Protocol on Prevention, Rescue, Repatriation and Rehabilitation, p. 35.

Ibid.

United States Department of Labor, 2013 Findings on the Worst Forms of Child Labor: India, 2014, p. 1.
} 
and transport resources that are generally unavailable at present. There is no clearly defined responsible party for arranging and funding the transfer of rescued children back to their home state. In the case of long-distance returns, as from Rajasthan to Bihar, groups of rescued children are sent by train to large regional railway hubs accompanied on an ad hoc basis by either a government official or NGO worker. Once traced, the family is told to come and collect the child from the regional hub.

Resources to strengthen a child's integration back into the family, to support parents' mentorship and acceptance of returned children are also lacking. As a result, reintegration is generally reduced to simple return to the status quo preceding the child's trafficking. Alternative accommodation options are also limited, underfunded, and not subject to adequate monitoring and evaluation. It is not surprising, given this reality, that reports of assault, neglect and re-trafficking in these environments are not uncommon. ${ }^{27}$

The NCLP schools are designed to provide rescued children with non-formal educational services that help them catch up on missed years. In these 'bridge schools', pupils are taught a highly condensed syllabus before being mainstreamed into a formal institution, or returned to some form of self-employment. NCLP schools also serve as the principal vehicle for provision of vocational training and regular health check-ups, which are conducted on a largely ad hoc basis. ${ }^{28}$

According to the study results, rescued children are not consistently enrolled in bridge school programmes after their return home. One CWC official stated that 'only the parents of the child have a role in school enrolment'. Participants listed several barriers to enrolment, most prominently the lack of available participating schools in the district, the failure of schools to deliver the promised daily stipend to formerly trafficked children, and the child's simple refusal to attend. Research shows that family mentorship and support are critical in school attendance in India. ${ }^{29}$ However, parents are not provided with financial, logistical and emotional services that would make it possible for them to play this role. Other reports show that the NCLP is significantly underfunded $^{30}$ - it operates in only about a third of India's 676 districts ${ }^{31}$ and its teaching staff is poorly remunerated and often under-qualified. ${ }^{32}$ Quality education that delivers valuable learning skills and tools to progress to higher education is critical, acting as a self-reinforcing mechanism to promote families' investment in getting their children to go to school. ${ }^{33}$ Inadequate bridge schools produce the opposite result.

Even when they are successfully enrolled in bridge schools, returned children face difficulties integrating into formal schools because the coordination between the two systems is extremely poor. This serious problem is partly exacerbated by the fact that bridge school programmes are run by the Ministry of Labour and Employment, while the Ministry of Education organises formal schooling. ${ }^{34}$ The failure to invest in robust teaching facilities in bridge schools and to ensure smooth transition opportunities into mainstream formal education is a critical issue in the reintegration context.

Indian reintegration policy seeks to support the social and economic viability of children and their families through a lump sum compensation scheme. The Supreme Court determined in the case of M C Mebta versus

27 See: Aangan India, Changing Spaces; US Department of State, Trafficking in Persons Report 2013 - India; A Kannampilly, "Culture of Abuse" at India's Children's Care Homes', The National, 15 July 2012, https://www.thenational.ae/world/asia/culture-of-abuse-at-india-s-children-s-care-homes-1.457713.

28 A K Satpathy et al., Rehabilitation of Child Labour in India: Lessons learnt from the evaluation of NCLPs, V.V. Giri National Labour Institute, 2010, p. 5.

29 O Kelly, J Bhabha and A Krishna, 'Champions: Exploring the determinants of adolescent girls' empowerment', Human Rights Quarterly, vol. 37, no. 4, 2015.

30 M Yamini et al., Human Rights and Budgets in India, 2009, p. 365.

31 Ministry of Labour and Employment, Annual Report of the Ministry of Labour and Employment 2012-2013, 2013.

32 B Zutsi, Seeking to Bridge the Divide: Linking formal and non-formal education in Uttar Pradesh India, UNESCO International Bureau of Education, 2004, p. 8,

33 A Banerjee and E Duflo, 'Top of the Class' in Poor Economics: A radical retbinking of the way to fight global poverty, Public Affairs, New York, 2011, pp. 71-101.

34 Notably, the one district where the NCLP is run by the Department of Education is Andhra Pradesh, where existing best practices have been identified and significant gains have been made in eliminating child labour. See: M Weiner, $\mathrm{N}$ Burra and A Bajpai, Born Unfree: Child labour, education, and the state in India, Oxford University Press, Oxford, 2007, p. Lvii. 
State of Tamil Nadu that offending employers must by law deposit INR 20,000 per rescued child into a special welfare fund. ${ }^{35}$ It also directed that one adult member of the child's family should be offered employment or, failing that, the state should contribute an additional INR 5,000 to the welfare fund. ${ }^{36}$

Respondents in the study were uniformly aware that rescued children ought to receive these sums but they acknowledged that, in practice, children rarely receive any compensation at all. This confirms other reports that compensation rarely reaches the intended beneficiaries. ${ }^{37}$ As an NGO representative commented, "There is no chance of financial help or compensation. It is believed that child's freedom is itself a compensation.' Importantly, respondents did not list the lack of resources as the principal reason why children are not compensated. They pointed to noncompliance by employers or technical and administrative failures. Policy frameworks do not provide clear, standardised guidelines on how cash transfers are meant to work. Neither the Protocol nor the MC Mebta judgment details where the welfare fund for receipt of the money should be set up, how interstate coordination should be achieved, or what kind of access families will have to this money.

Families need structured and ongoing support to mitigate the risk that a child will be re-trafficked for economic reasons. The research suggests that cash transfers are most effective in impacting child labour when integrated with other investments in health, education facilities or afterschool education-part of a radical, sustained poverty-alleviation strategy. ${ }^{38}$ Lump sum compensation does little to address the structural factors that lead households to use child labour as a coping strategy. ${ }^{39}$

Finally, the acute mental and physical health needs of rescued children are acknowledged as an afterthought, without concrete policy initiatives to ensure delivery of suitable and sustained services. Although study participants stated that a counsellor is supposed to accompany children immediately following rescue, no other concrete measures were mentioned that address the physical, mental, and psychological needs of these vulnerable individuals or those of their families.

\section{Implications for Improved Responses to Child Labour Trafficking}

\section{An Increased Focus on Prevention}

This study of the system in place for protecting and supporting children trafficked for labour between Bihar and Rajasthan clearly demonstrates that current efforts do not engage with the broader structural drivers of this problem, including the vulnerability of the family as a whole. The precise long-term effects of these failures have yet to be studied in detail. However, participating CWC members stated that many children are rescued more than once, confirming the widely acknowledged fact that re-trafficking is a widespread problem. ${ }^{40}$ For many of these children and their families, child labour may still appear the best of a set of limited options.

The recruitment of children for the purpose of labour exploitation is in a sense epiphenomenal: the result of a radically deficient approach to harm prevention, and of multiple, critical protection failures across the home, community, school, health, law enforcement, welfare system, and economy. Current legal and policy frameworks for rescue and reintegration are intended to address some of these same protection failures for

35 M C Mehta v. State of Tamil Nadu \& Ors (1996), RD-SC 1576, http://ncpcr.gov.in/show_img.php?fid=520.

36 Protocol on Prevention, Rescue, Repatriation and Rebabilitation, p. 32.

37 See, for example, A Banerji, 'NCLP teachers without salary for past 21 months', The India Tribune, 28 March 2015, http://www.tribuneindia.com/news/jalandhar/nclp-teachers-without-salary-for-past-21-months/59857.html; Human Rights Watch, Small Change: Bonded child labour in India's silk industry, January 2003, http://www.hrw.org/reports/2003/india/.

38 J de Hoop and F Rosati, 'Cash Transfers and Child Labor', World Bank Policy Research Working Paper No. 6826, 1 March 2014, p. 30, http:// elibrary.worldbank.org/doi/abs/10.1596/1813-9450-6826.

39 Ibid., p. 23.

40 The National Commission for the Protection of Child Rights has estimated that of the children who are trafficked in India, 92 per cent have not been rescued, 6 per cent have been rescued once, and 2 percent have been rescued twice. See: Committed Action for Relief and Education (CARE) \& Child Rights and You (CRY), Developing a New Perspective on Child Labour: Exploring the aftermath of Mumbai raids conducted from 2008 onwards, 2014, p. 3, http://www.cry.org/resources/pdf/CRY-CARE-report-on-Child-Labour-2014.pdf. 
children who have already been trafficked. This reactive approach must be complemented by preventative interventions that address the factors widely known to render children vulnerable to future victimisation.

A preventative approach to child trafficking would link top-down coordination of child protection inputs to carefully targeted and sustained poverty reduction measures. Norm change within communities where children have historically been trafficked will only happen when viable alternative survival strategies are evident. To this end, greater investment in quality public education, a sector that in 2016-17 received only 3.65 per cent of India's GDP, is a particularly pressing priority. Low investment in education, health and social welfare also leads to under-utilisation of existing funds, as effective implementing governance systems are not established. For example, official data show that between 21 and 41 per cent of funds allocated for elementary education went unutilised between 2011 and 2016.41

A preventative approach would also complement these more traditional development efforts with targeted community-level initiatives to build alliances between families, local government bodies and service providers, ranging from healthcare workers to the police. These are the actors best positioned to identify and assist minors at particular risk of trafficking and their families, offering them relevant information on risks as well as concrete supports. Community-level prevention programmes would help children and families capitalise on programmes and services already established to assist them and designed to target the vulnerabilities that lead to trafficking. They would also strengthen the workings of the programmes themselves by increasing accountability and identifying areas for improvement.

One such programme is run by the non-profit Aangan in Bihar and five other states in India. Introduced in 2014, it provides a year-long training to a cohort of local women as community-level child protection volunteers. The women become respected and knowledgeable point persons for children's issues within their communities, a front line for pre-empting and addressing harm. They regularly collect information on the ongoing needs of children within their community, entering the data into a mobile app, that is then used to identify vulnerable children. The collected information not only drives timely interventions for children and families but also strengthens policymaking at the local level. The child protection volunteers develop working relationships with local officials and service providers, and together improve the services delivered to their communities.

In general, prevention remains an under-funded and under-researched area: robust evidence on the efficacy and impact of community-level preventative initiatives is necessary to secure long-term investment by governments and donors.

\section{Strengthening Existing Remedial Approaches}

The grim reality of pervasive child labour trafficking in India requires remedial interventions that support victims and their families, and prevent repeated situations of exploitation. The Harvard FXB study identifies several challenges to the rescue and reintegration model established in India for this purpose. ${ }^{42}$

Critical failures in cross-stakeholder coordination and communication mean that actors do not work together to implement the child's rescue and reintegration plan in a holistic manner. Correcting this problem is no simple task. Rescue and reintegration involve multiple actors that are separated by distance, rigid departmental mandates and, often, language barriers. There is no established protocol for regular communication between relevant partners, responsibilities are not clearly assigned, and effective monitoring of services is lacking. Networking links between employees of the implicated agencies are non-existent. As a result, government stakeholders routinely evade responsibility, deflecting blame for protection failures.

41 Comptroller and Auditor General (CAG), Report on Implementation of Right of Children to Free and Compulsory Education Act, 2009, Indian Government Ministry of Human Resource Development, 21 July 2017.

42 The FXB Centre has developed a detailed set of policy recommendations resulting from this analysis that can be found at the FXB website. See: E Donger and J Bhabha, Is This Protection? Analyzing India's approach to the rescue and reintegration of children trafficked for labour exploitation, The FXB Center for Health and Human Rights at Harvard University, 2016, https://cdn2.sph.harvard.edu/wp-content/uploads/sites/5/2016/03/Is-this-Protection-Final.pdf. 
Poor information sharing between agencies involved in rescue and reintegration is exacerbated by a lack of reliable data and a centralised database. There is no formal mechanism to enable a CWC member in Bihar to get information about a child rescued from Jaipur. A centralised intelligence system that includes both police and non-police monitoring information and details of available regional resources is essential to rescue and reintegration success. Development of a secure shared database with varying levels of access for different stakeholders that collates case information is an urgent priority, and an initiative that could be spearheaded by concerned NGO partners. The Harvard FXB team received several requests for such facilities from interested stakeholders.

Essential though it is, a centralised database will not solve the existing challenges concerning information sharing and collaboration without a network of trained and skilfully supervised staff dedicated to overseeing the multifaceted intervention process and encouraging norm change at the grass-roots level. No such network is in place at the moment: the AHTUs established to address child labour trafficking lack the guidelines, resources, and external supervision or monitoring required to fulfil this role.

An identified office holder accountable for the coordination and oversight of the entire rescue and reintegration processes should supervise training programmes for all key stakeholders on their respective roles and responsibilities and on the challenges facing child victims of trafficking. The process would include instruction in child rights principles and involve clear lines of collaboration and coordination with all relevant stakeholders, regular information exchange and trainings. The ability to secure adequate, long-term funding and technical support programmes, guaranteed by dedicated line items in state government budgets, would be a critical component of the leadership role required. A collective effort to review improvements on the ground, with periodic high-profile meetings and reward ceremonies, might also assist the process of strengthening the anti-trafficking programme.

Another crucial issue identified by the Harvard FXB study is a lack of standardised training programmes for implementing partners. Anti-trafficking personnel lack a thorough and reliable grasp of children's rights and of relevant policies and regulations, and they frequently fail to take advantage of resources that could be utilised to promote more effective interventions. Networking opportunities between employees of the implicated agencies are also non-existent.

Financial issues also plague the rescue and reintegration model. The Harvard FXB study highlighted the existence of considerable financial resources for rescue and reintegration that are being ineffectively allocated. Central among these are stipends payable to formerly trafficked children. These funds remain unused largely due to lack of clear guidelines for their disbursement. As a result, some valuable opportunities for protection and sustainable reintegration are squandered.

At the same time, it is clear that a greater allocation of consistent funding streams to support rescue and reintegration services is needed. Current structural limitations often leave rescue and reintegration actors with impossible choices. Return home may not be in the long-term best interests of the child, yet alternatives such as foster care, orphanages, hostels or kinship care may also present significant risks to the child. Among the many programmes that require such funding are the following: (i) the complex and costly services needed to support bridge schools; (ii) income generation and family-strengthening projects for children's relatives, and (iii) alternative accommodation options for children whose best interests would be served by outside family care.

Because of the enduring organisational and structural challenges, a sizeable share of current rescue and reintegration work is outsourced to the non-profit sector. ${ }^{43}$ NGOs have flexible mandates and in-depth knowledge of local communities that enable them to operate effectively in areas where government presence is limited and to provide services inadequately covered by existing policy. ${ }^{44}$ These programmes are also almost

43 Dr A K Vaddiraju, Sisyphean Efforts? State policy and child labour in Karnataka, Cambridge Scholars Publishing, Cambridge, 2013, p. 5.

44 J Clark, 'The State, Popular Participation, and the Voluntary Sector', World Development, vol. 23, issue 4, 1995, pp. 593601; B Ghosh, 'NGOs, Civil Society and Social Reconstruction in Contemporary India', Journal of Developing Societies, vol. 25, issue 2, 2010, pp. 229-252. 
entirely outside the reach of public control or oversight. ${ }^{45}$ Many are chronically underfunded, dependent on external support for their survival and, as a result, precariously positioned to provide consistent service over time. ${ }^{46}$ These vulnerabilities frequently result in inadequate staff training and high turnover, which in turn lead to low quality services, and compromise the ability to provide long-term sustainable solutions.

Despite the vibrancy and flexibility of the non-profit child protection sector, it is clearly a poor substitute for legally mandated government services, provided the latter are appropriately funded and supported. As the UN Special Rapporteur on the sale of children, child prostitution and child pornography has noted, 'States bear the primary responsibility in the design and implementation of programmes, policies and services to ensure the right to care, recovery and reintegration of children, including their timely identification as victims. ${ }^{37}$

Government-NGO partnerships should be created and maintained through a standardised process that better synchronises non-profit efforts with existing initiatives, ensures long-term funding and rigorous ongoing training, monitoring and evaluation. This process should begin with careful evaluation of successful partnerships leading to effective scaling. The bridge-school model spearheaded by the MV Foundation, and widely replicated by the Andhra Pradesh government in its 'Back to School Project' is a case in point. ${ }^{48}$

\section{Conclusion}

Several recent developments in Indian law impact protections for children trafficked for labour. In addition to the aforementioned amendment to the country's child labour law, which dramatically expands the scope of legal work for children under 14, the Ministry of Women and Child Development proposed a new antitrafficking bill in June 2016. This Trafficking of Persons (Prevention, Protection and Rehabilitation) Bill, still in draft form at the time of writing this article, has been applauded for strengthening criminal investigation and prosecution processes. However, like its predecessors, it fails to provide clear guidelines on what 'rehabilitation' of victims must include and who is responsible for providing it.

The evidence presented here on rescue and reintegration in India indicates that reforms are needed to improve the policy itself; to strengthen the implementation of the policy; and to direct efforts as early as possible to prevent victimisation of trafficked children before harm occurs. Current efforts, despite their scale and complexity, have failed to protect the rights of vulnerable children or address the endemic causes of their abuse. The strategic and fiscal costs associated with the ambitious process outlined here, significant though they are, are far outweighed by the enormous costs of continued inaction, and the human and social toll of current failures in rescue and reintegration policy.

Elizabeth Donger is a Research Associate at the FXB Center for Health \& Human Rights at Harvard University. Her work focuses on distress migration and child protection, with a focus on partnerships between the state and civil society, identity and access to justice. She is currently working with Professor Bhabha on a study of three Indian non-profit organisations' community-level harm prevention strategies to build child protection and rights. She holds a Master of Public Policy from the Harvard Kennedy School. Email: edonger@hsph.harvard.edu

Jacqueline Bhabha is Director of Research at the FXB Center for Health and Human Rights, a Professor of the Practice of Health and Human Rights at the Harvard Chan School of Public Health, and the Jeremiah Smith Jnr. Lecturer in Law at Harvard Law School. She has published extensively on issues of transnational child migration, refugee protection, children's rights, and citizenship. She is currently leading several research projects on distress youth migration in the Mediterranean basin and on harm prevention and capacity building in the child protection field. Email: jacqueline_bhabha@harvard.edu

45 S Hameed et al., Human Trafficking in India: Dynamics, current efforts and intervention opportunities for the Asia Foundation, The Asia Foundation, 2010, p. 40.

46 Ibid., p. 41.

47 UN Human Rights Council, Report of the Special Rapporteur on the sale of children, child prostitution and child pornography, Maud de Boer-Buquicchio, A/70/222, 70th Session GA, 2015, p. 7.

48 Ibid., p. 11. 